\title{
Determinação de material particulado em indústria siderúrgica: estudo de caso
}

\author{
RESUMO
}

Emanoelen Bitencourt e Bitencourt

manuhbitencourt13@outlook.com Universidade do Estado do Pará (UEPA), Marabá, Pará, Brasil

Evandro Wernner Campelo Farias "In Memorian"

Universidade do Estado do Pará (UEPA), Marabá, Pará, Brasil

Thais Binow Dias

binowthais123@gmail.com

Universidade do Estado do Pará

(UEPA), Marabá, Pará, Brasil

Vanessa Silva Oliveira

voliveiraambiental@gmail.com

Universidade do Estado do Pará

(UEPA), Marabá, Pará, Brasil

Eduarda Costa Ferreira eduardacostaferreira5@gmail.com Universidade do Estado do Pará (UEPA), Marabá, Pará, Brasil

Glauber Epifânio Loureiro epfanio@uepa.br

Universidade do Estado do Pará (UEPA), Marabá, Pará, Brasil

\begin{abstract}
Apesar da indústria de ferro-gusa ser de grande importância para o crescimento econômico e geração de emprego é um agravante no que tange a qualidade do ar, visto que está relacionada ao lançamento de poluentes que afetam a saúde da população, como os particulados. Estes fatos justificam a pesquisa, a qual teve o propósito de avaliar a quantidade de Partículas Totais em Suspensão (PTS) presente no ar atmosférico ao entorno de um parque siderúrgico no Sudeste do Pará, comparar com os valores da resolução CONAMA $n^{\circ} 3$ de 1990 e relacionar estes dados com o índice pluviométrico e a produção no alto-forno e na aciaria da indústria siderúrgica. Assim, foi utilizado um Amostrador de Grande Volume (AGV) para a quantificação do material particulado e os procedimentos seguiram a orientação da NBR 9547 (ABNT) e do manual da Energética. Os dados obtidos indicaram que a indústria controlou o material emanado no período analisado, entretanto não esteve de acordo com a norma, pois ultrapassou a quantidade permitida. Além disso, o índice pluviométrico, as produções na aciaria e no alto-forno exerceram influência na concentração de PTS.
\end{abstract}

PALAVRAS-CHAVE: Material Particulado. Siderurgia. Amostrador De Grande Volume. 


\section{INTRODUÇ̃̃O}

$\mathrm{O}$ ar, outrora abordado como um recurso que teria sempre boa qualidade passou a representar uma grande preocupação desde meados do século $X X$, pois a partir do desenvolvimento industrial e dos processos produtivos surgiram novas fontes de poluentes de maneira desenfreada, com aumento da poluição atmosférica e consequentes danos significativos ao meio ambiente e à saúde da população (DAPPER; SPOHR; ZANINI, 2016).

Nesse contexto, a poluição atmosférica pode ser entendida como a existência de elementos perigosos na atmosfera, em concentrações capazes de perturbar a estabilidade deste meio ambiente, incluindo toda a biota, como os seres humanos, flora e fauna. Ademais, esse tipo de poluição também influencia na degradação de bens culturais de entretenimento (DRUMM et al., 2014).

Esta poluição, no meio urbano, aumentou consideravelmente, seja por fontes móveis ou fixas. Os poluentes emitidos são diversos, visto que são de fontes distintas, e isto exerce influência nas características do ar. Além disso, a dissipação está condicionada a diversos aspectos, geralmente associados entre si, como topografia, o uso da terra, tipos de construções, nível de circulação de veículos e condições do tempo e/ou clima (BLUME et al., 2014; ZHENG; LIU; HSIEH, 2013).

Entretanto, a atenção com a poluição atmosférica se tornou relevante depois de graves casos na saúde pública, atrelados às áreas de atividade industrial, como o caso de Carajás no Brasil, por exemplo. O polo mineirometalúrgico de Carajás foi citado no documento da Comissão Interministerial para a Preparação da Conferência das Nações Unidas sobre Meio Ambiente e Desenvolvimento por conta dos problemas ambientais. No referido polo, estavam aglomeradas indústrias de ferro-gusa (JURAS, 2015).

Essa atividade impacta significativamente na degradação da qualidade do ar porque, apesar das indústrias siderúrgicas serem importantes na economia e geração de empregos, elas representam fontes de poluição consideráveis, por conta dos processos produtivos, desde a retirada do minério, modificação em alto-forno e aciaria, os quais geram grande quantidade de poluentes atmosféricos, notavelmente emissão de óxidos e material particulado (ROCHA; GUIMARÃES, 2017).

Nessa perspectiva, no intuito de assegurar a saúde e bem-estar das pessoas há um limite de concentração permitido para cada poluente atmosférico, determinado pela Organização Mundial da Saúde - OMS, como o valor de concentração ou deposição admitido pela legislação, os limites estabelecidos pela Resolução CONAMA n. 3:90, a qual dispõe sobre os poluentes e o material particulado. Este material pode proceder da emanação dos próprios particulados, dos que passaram por processos de alteração química ou das emanações dos gases que condensam; e pode reter gases no exterior da partícula, o que implica na sua propagação (SANTOS; CARVALHO; REBOITA, 2016).

Para tanto, a fim de verificar se as emissões enquadram-se nos padrões ambientais determinados é imprescindível um acompanhamento desses fatores, o que possibilita atestar a conformidade de um empreendimento com a 
legislação, além de uma melhor tomada de decisão para o controle e avaliação da qualidade ambiental (CAMPOS; MARQUES, 2016).

Portanto, as indústrias representam fontes de poluição e alteração da qualidade do ar, fato que justifica esta pesquisa, a qual objetivou determinar quantitativamente as Partículas Totais em Suspensão (PTS) em uma siderúrgica, a partir do uso de um Amostrador de Grande Volume (AGV), a fim de comparar os dados obtidos com os padrões da legislação vigente, e relacionar estes com o índice pluviométrico e a produção no alto-forno e na aciaria da indústria siderúrgica.

\section{FUNDAMENTAÇÃO TEÓRICA}

\section{EFLUENTES ATMOSFÉRICOS DA SIDERURGIA}

Apesar da indústria do aço ser um setor que desempenha papel importante na economia e competitividade no mercado mundial, segundo Almeida et al. (2015) é também um polo de grandes desafios ambientais devido ao alto consumo de energia e matéria-prima, e consequentemente, de geração de resíduos e efluentes.

Isto se deve a grande quantidade de reações físico-químicas nas etapas de transformação do minério de ferro e combustível, seja ele mineral ou vegetal, para obtenção do aço laminado (CARVALHO; MESQUITA; ARAÚJO, 2015).

Quanto aos efluentes atmosféricos, Silva et al. (2016) cita a emissão de óxidos de carbono, enxofre e nitrogênio (COx, SOX, NOx, respectivamente); compostos orgânicos voláteis ( $\mathrm{COV})$; dioxinas; metano $(\mathrm{CH} 4)$; benzeno $(\mathrm{C} 6 \mathrm{H} 6)$; fenóis; compostos alifáticos; amônia ( $\mathrm{NH} 4)$; naftaleno (C6H10); cianetos; sulfetos e materiais particulados (MP).

Ademais, Silva e Vieira (2018) apontam as diferentes fontes de emissões na planta siderúrgica, como as de fontes estacionárias (exaustores de silos de descarga de carvão vegetal e minério de ferro, chaminés, queimadores dos gases excedentes dos altos fornos), de fontes móveis (automóveis) e de fontes difusas (junção do tráfego de veículos com o manuseio de matérias-primas nos pátios da indústria).

No que tange a emissão de efluentes atmosféricos, em cada fase da rota de produção do aço pode-se mencionar os mais relevantes, na preparação das cargas com a pelotização, ao formar material particulado, NOx, dióxido de enxofre ( $\mathrm{SO} 2)$, ácido clorídrico $(\mathrm{HCl})$, ácido fluorídrico $(\mathrm{HF})$; a geração de material particulado, monóxido de carbono (CO), dióxido de carbono (CO2), SO2, NOx, COVs, benzeno, hidrocarbonetos aromáticos policíclicos (HAPs) e $\mathrm{CH} 4$ na coqueificação; e material particulado, $\mathrm{CO}, \mathrm{CO} 2, \mathrm{SO} 2$, $\mathrm{NOx}, \mathrm{COVs}, \mathrm{HCl}, \mathrm{HF}$, dioxinas e furanos como dibenzeno-p-dioxinas e dibenzofuranos (PCDD e PCDF) na sinterização (ALMEIDA et al., 2015).

Em sequência, na fase de redução química e física das cargas e refino do ferro-gusa produzido, há no alto-forno a formação da maior quantidade de material particulado (cerca de 45\%), bem como, emissão de $\mathrm{CO}, \mathrm{CO} 2, \mathrm{SO} 2$, NOX, COVs, $\mathrm{HF}, \mathrm{HCl}$. Já na aciaria LD, há geração de material particulado, o qual pode 
ser composto por óxidos de ferro (maior percentual), metais traços e fluoretos, metais como o zinco, $\mathrm{CO}, \mathrm{COVs}, \mathrm{HF}$ e $\mathrm{HCl}$; e quando usa-se aciaria elétrica, existe a produção de material particulado, metais (zinco, chumbo, mercúrio e outros), CO2 e dioxinas (CAVALCANTI, 2012; CARVALHO; MESQUITA; ARAÚJO, 2015).

Posteriormente, no final do processo, a etapa de lingotamento não apresenta geração de efluentes significativos. Todavia, no acabamento (laminação) verifica-se a geração de material particulado, CO, CO2, SO2, NOx, COVs e vapores ácidos (CAVALTANTI, 2012; CARVALHO; MESQUITA; ARAÚJO, 2015).

\section{Material Particulado}

O material particulado (MP) é um dos mais importantes poluentes transportadores na atmosfera, advindo principalmente de fontes antropogênicas, como atividades industriais, construção civil, trafego de veículos, movimentação de solo, mas também, pode ser de fontes naturais como a vegetal (polinização), oceânica e vulcânica (CONCEIÇÃO, 2017; FRANCOVÁ et al., 2017).

Pode-se definir o MP como:

Uma variedade de partículas e gotas (aerossóis) pequenas e leves o suficiente para permanecerem suspensas na atmosfera substâncias constituídas de poeiras, fumaças ou qualquer outro material nos estados sólido e líquido que se mantenham suspensos no ar, em função do seu tamanho (GOMES, 2016, p. 17).

Já Cunha (2016, p. 30) afirmou ser um "termo genérico para uma vasta gama de substâncias químicas existentes na atmosfera na forma de partículas, tanto sólidas quanto líquidas e de diversos tamanhos". Pode-se dizer também que a composição é variável, determinada pela capacidade de absorção e associação das partículas finas, que juntamente com outras características podem ser classificadas pelo formato, tamanho e composição (OLIVEIRA, 2014).

\section{Classificação por formato}

Os formatos dos MP's podem ser classificados como poeira, a qual é proveniente da desagregação mecânica como, por exemplo, moagem, britagem e abrasão, com diâmetro entre 0,01 a $100 \mu \mathrm{m}$, não esféricas. Outro formato são os fumos, que são formados pela mudança de fase como a sublimação de sólidos e condensação de gases ou até mesmo por combustão e fundição, de tamanho reduzido e formato esférico próximo a $1 \mu \mathrm{m}$ (KOYAMA, 2014).

Além do mais, têm-se as fumaças, que consistem em um subproduto da combustão incompleta de materiais orgânicos (lenha, óleos, combustíveis, dentre outros) e apresentam, em geral, diâmetro menor que $0,5 \mu \mathrm{m}$ e; as névoas, caracterizadas por serem partículas líquidas geradas pela condensação ou dispersão de líquidos - atomização - como de agroquímicos, e estas possuem um diâmetro normalmente maior que 5 Hm (CUNHA, 2016; MONDO, 2011). 
Os tamanhos atribuídos aos MP's no Brasil são identificados, conforme a classificação da CETESB (2018), como Partículas Totais em Suspensão (PTS) com diâmetro de até $50 \mu \mathrm{m}$, Partículas Inaláveis (MP10) com diâmetro de até $10 \mu \mathrm{m}$ e Partículas Inaláveis Finas (MP2,5), apontam Medeiros, Saraiva e Saboia (2018). Entretanto, a Agencia de Proteção Ambiental dos Estados Unidos - United States Environmental Protection Agency (USEPA) - distribui as partículas em 4 grupos, são eles: nucleação, Aitken, acumulação e o grosseiro (USEPA, 2004).

Em conformidade com a USEPA (2004), o modo de nucleação é integrado por partículas recentes, com diâmetro abaixo de 0,01 $\mu \mathrm{m}$. Já o modo Aitken engloba aquelas com o diâmetro no intervalo de 0,01 a 0,1 $\mu \mathrm{m}$, em que a origem pode ser do crescimento de partículas do modo de nucleação ou pela nucleação de elevadas concentrações de substâncias precursoras.

O terceiro modo é o de acumulação, com partículas de diâmetro compreendendo de 0,1 a $1 \mu \mathrm{m}$, sendo as responsáveis pela maior parte da área específica do material particulado, de acordo com USEPA (2004). Ademais, Camara (2015) afirma a existência de uma maior capacidade de absorção/adsorção de gases nesse modo, assim como mais resistência à remoção, permanecendo por mais tempo na atmosfera, características que o levaram a ser o principal alvo de estudos epidemiológicos.

Por fim, as partículas grosseiras são aquelas compreendidas com o diâmetro entre 1-3 $\mu \mathrm{m}$, conforme USEPA (2004). A origem deste MP pode ser da quebra de materiais de maiores tamanhos, como os advindos de atividade da construção civil e movimentação de solo, porém, a permanência em suspensão é menor (SOARES, 2017).

\section{Classificação por composição}

A composição dos MP's é variável, uma vez que as matérias-primas de origem e os processos nos quais deram origem são distintos. Nos processos siderúrgicos, por exemplo, os materiais comuns são alumínio, ferro, cálcio, silício e oxigênio na forma de óxidos ou silicatos, justamente os mais associados às classes PTS e PM10. Já partículas abaixo de PM2,5 são constituídas geralmente por cristais pequenos de carbono, compostos inorgânicos de enxofre e nitrogênio, além disso, podem conter metais traços com percentual de até $75 \%$ (OLIVEIRA, 2014).

\section{MATERIAL E MÉTODOS}

Os materiais utilizados para as mensurações foram Amostradores de Grande Volume (AGV) para Partículas Totais em Suspensão (PTS), com vazão variável, e filtros de fibra de vidro, ambos da marca Energética; e balança analítica.

O método adotado foi o dedutivo, pois a atividade industrial contribui para a diminuição da qualidade do ar, e na cidade do estudo existe atividade industrial. A abordagem da pesquisa foi quantitativa, com natureza aplicada e procedimento exploratório. 0 método em questão foi atrelado ao levantamento 
de dados bibliográficos e documentais, no período de 2011 a 2018, exceto pelas normas legais (PRODANOV; FREITAS, 2013).

\section{CARACTERIZAÇÃO DA ÁREA DE ESTUDO}

A empresa do estudo localiza-se no Sudeste do Pará e é caracterizada por ser uma siderúrgica integrada, onde os processos de produção são divididos em quatro etapas. A primeira etapa ocorre nos Altos-fornos onde é a realizada a redução do minério de ferro em ferro-gusa, a etapa seguinte é feita na Aciaria, chamada de refino da mistura de sucata ferrosa e gusa líquida para a produção de aço.

Posteriormente, acontece uma terceira etapa, a Laminação, onde o aço em forma de tarugos é aquecido a $1.100^{\circ} \mathrm{C}$ e deformado mecanicamente para a produção de laminados, como vergalhões e fio-máquina. Por fim, na trefila, quarta etapa do processo, o fio-máquina é deformado a frio, para obtenção de arames industriais, arames para construção civil e arames recozidos.

\section{AMOSTRAGEM}

As partículas totais em suspensão (PTS) foram coletadas em quatro pontos, a partir de quatro amostradores de grandes volumes - AGV PTS 1, próximo ao prédio de apoio, descarga de carvão e alto-forno; AGV PTS 2, próximo ao prédio administrativo, pátio de sucata 01 e laminação; AGV PTS 3, próximo ao decantador, aciaria e almoxarifado; AGV PTS 4, próximo a trefila e pátio de sucata 02 - a cada 6 dias, de março de 2014 a fevereiro de 2015, que resultou em 59 amostras para cada ponto, totalizando 236 amostras.

Os procedimentos adotados para a realização da amostragem foram conforme o especificado por Brasil (1997), e pelas diretrizes do manual de operação do AGV PTS da Energética (2016), o qual dispõe sobre o processo na coleta das amostras e sobre a determinação da concentração de PTS (Equação 1).

$$
\mathrm{PTS}=\left(10^{6}\right) \frac{\mathrm{Mt}}{\mathrm{Vp}}
$$

Em que PTS = Concentração de Particulados Totais em Suspensão $\left(\mu \mathrm{g} / \mathrm{m}^{3}\right)$; $\mathrm{Mt}=$ Ganho líquido de PTS no filtro durante a amostragem (g); $\mathrm{Vp}=$ Volume total amostrado $\left(\mathrm{m}^{3}\right)$ e $10^{6}=$ Fator de conversão $(\mu \mathrm{g} / \mathrm{g})$.

Para tanto, fez-se o uso de planilha eletrônica do software Microsoft Office Excel, fornecida pela Energética (2016) e seguindo as condições de referência de Brasil (1990).

\section{ANÁLISE ESTATIÍSTICA}

Quanto a análise estatística dos dados obtidos, foi utilizada a Estatística Descritiva, por conta de o estudo apresentar um conjunto de dados, dos quais foram calculados, por meio de planilhas eletrônicas de Microsoft (2016), software utilizado também para a produção dos gráficos, valores de: máximo; mínimo; média; coeficiente de variação, em que a classificação da dispersão relativa dos dados foi baseada em Cherubin et al. (2015); variância, desvio padrão e 
assimetria, discutidos por Triola (2017); e o coeficiente da correlação de Pearson, do qual os valores de $r$ foram adaptados de Colvero et al. (2017).

\section{RESULTADOS E DISCUSSÃO}

\section{AMOSTRADORES}

\section{Amostrador De Grande Volume 1}

No AGV 1, próximo ao prédio de apoio, descarga de carvão e alto-forno, e o mais perto da rodovia, os dados obtidos indicaram que as concentrações máximas mensais durante a maior parte das amostragens permaneceram dentro do padrão de qualidade do ar primário diário $\left(240 \mu \mathrm{g} / \mathrm{m}^{3}\right)$, conforme Brasil (1990). Entretanto, o valor das PTS excedeu o padrão no mês de dezembro, sendo o maior valor obtido, de $359,84 \mu \mathrm{g} / \mathrm{m}^{3}$ (Figura 1 ).

Figura

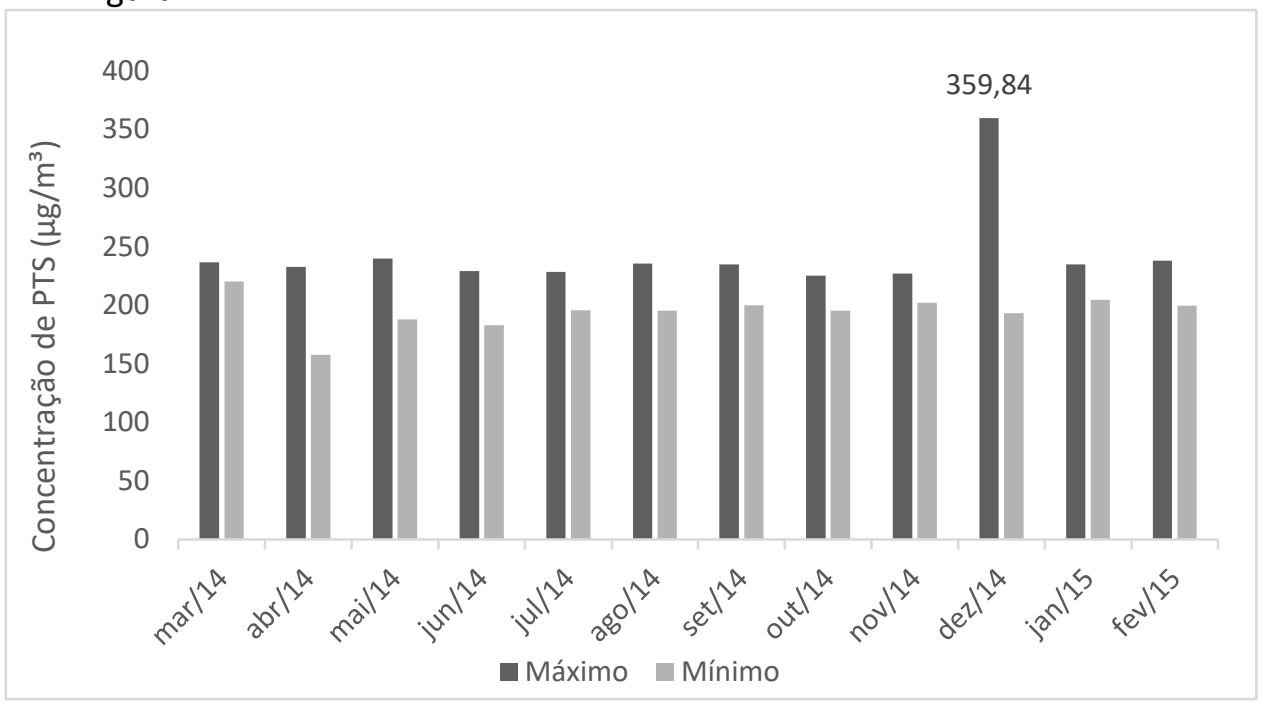

Valores máximos e mínimos de concentração de PTS no AGV 1

Fonte: Pesquisa de campo (2015)

De forma geral, no AGV 1, a média foi de $216,94 \mu \mathrm{g} / \mathrm{m}^{3}$, e apesar de uma concentração ter ultrapassado o limite estabelecido, os dados podem ser considerados homogêneos, com uma dispersão baixa em torno da média, pois o coeficiente de variação (CV), para este AGV, foi de $11,58 \%$.

Entretanto, a variância foi 631,84 e do desvio padrão $\pm 25,13$, os quais ainda que representem valores distribuídos de maneira mais homogênea, pois são os menores valores verificados, possibilitam deduzir que a concentração de PTS poderá, em algum momento, exceder o limite do padrão estabelecido em cerca de $2,07 \mu \mathrm{g} / \mathrm{m}^{3}$, visto que a distribuição foi assimétrica positiva, de 2,76 , isso reforça os dados obtidos para este AGV, pois esse fato sucedeu, só que com um valor máximo de $119,84 \mathrm{\mu g} / \mathrm{m}^{3}$ a mais do que o padrão. 
Em relação ao AGV 2, próximo ao prédio administrativo, pátio de sucata $01 \mathrm{e}$ laminação, e o segundo mais perto da rodovia, os dados obtidos indicaram que as concentrações máximas mensais não estiveram de acordo com o padrão de qualidade do ar primário diário $\left(240 \mu \mathrm{g} / \mathrm{m}^{3}\right)$, de acordo com Brasil (1990), visto que em setembro de 2014, com o segundo maior valor obtido, o valor foi de $350,82 \mu \mathrm{g} / \mathrm{m}^{3}$ (Figura 2).

Figura 2 - Valores máximos e mínimos de concentração de PTS no AGV 2

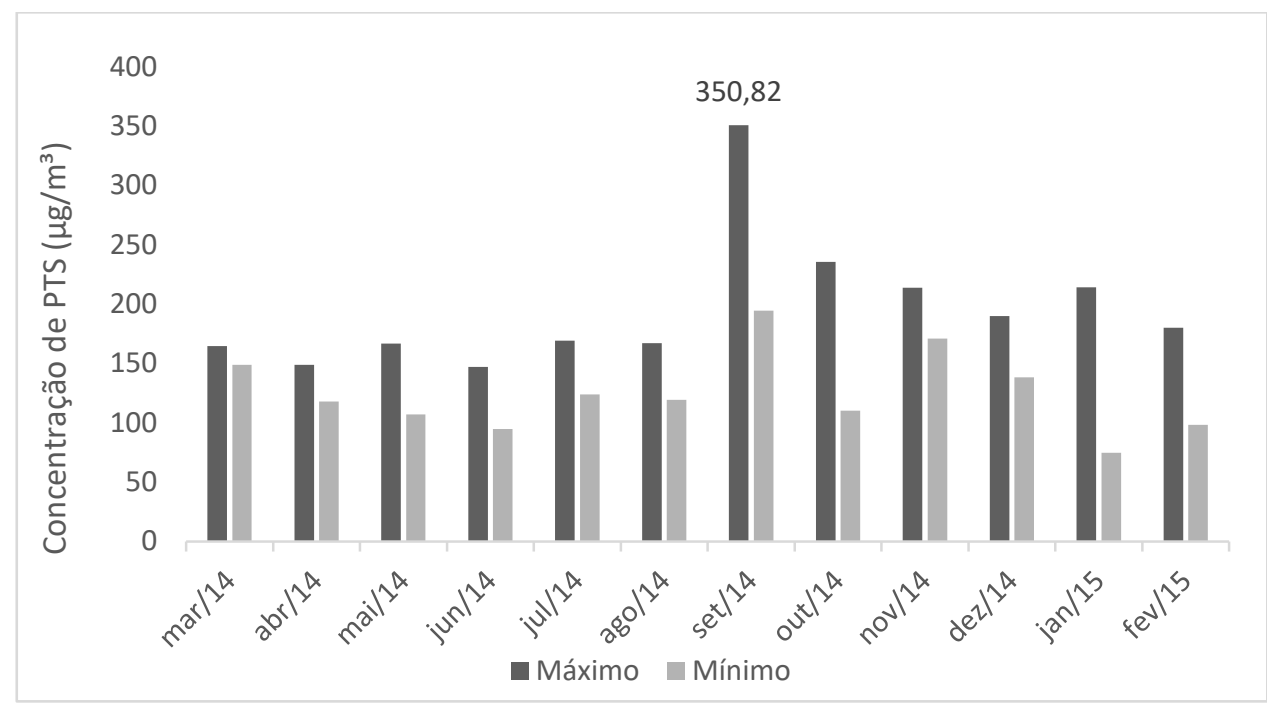

Fonte: Pesquisa de campo (2015)

Neste AGV, considerando todas as amostras, a média foi igual a 157,95 $\mu \mathrm{g} / \mathrm{m}^{3}$, com valores de dispersão média, em que o coeficiente de variação foi $29,74 \%$, superior ao AGV 1. Todavia, mesmo com uma variância de 2206,77 e o desvio padrão de $\pm 46,97$, valores também superiores ao AGV 1 , considerados moderadamente heterogêneos, e uma distribuição assimétrica positiva de 1,19, é possível inferir que a concentração de PTS não ultrapassará o padrão legal.

Porém, isto não aconteceu, e houve ultrapassagem em $110,82 \mathrm{\mu g} / \mathrm{m}^{3}$, referente ao valor máximo, provavelmente por conta da dispersão de PTS se relacionar a diversos fatores variáveis, como circulação de veículos nas proximidades, uso da terra, condições temporais e os próprios processos produtivos, indicam Blume et al. (2014) e Zheng, Liu e Hsieh (2013). Vale ressaltar que essas variações ocorrem diariamente, e podem ter influenciado o dia de amostragem de forma diferente dos dias entre amostragens.

\section{Amostrador De Grande Volume 3}

Já para o AGV 3, próximo ao decantador, almoxarifado e aciaria, os dados obtidos indicaram o cumprimento dos padrões estabelecidos, para as concentrações máximas mensais, com relação ao padrão de qualidade do ar primário diário $\left(240 \mu \mathrm{g} / \mathrm{m}^{3}\right)$, em conformidade com Brasil (1990) (Figura 3). 
Figura 3 - Valores máximos e mínimos de concentração de PTS no AGV 3

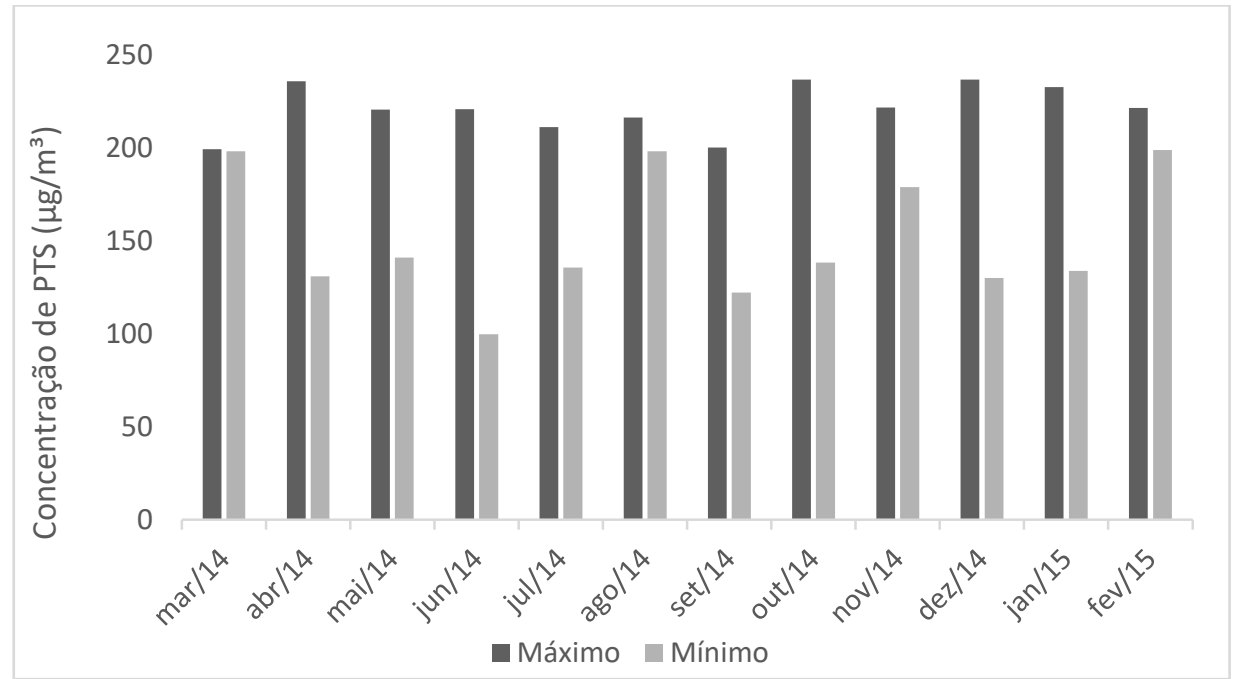

Fonte: Pesquisa de campo (2015)

Em relação à média do $A G V 3$, foi de $186,04 \mu \mathrm{g} / \mathrm{m}^{3}$, e os valores representaram uma dispersão média também, com um coeficiente de variação de $18,69 \%$. Neste AGV, a variância foi 1209,76 , e o desvio padrão $\pm 34,78$, valores próximos ao $A G V$ 2 , um pouco heterogêneos, porém com uma distribuição assimétrica negativa, de $-0,57$, o que possibilita deduzir que a concentração de PTS não extrapolará o padrão determinado, corroborando com o resultado encontrado para este AGV.

\section{Amostrador De Grande Volume 4}

No AGV 4, próximo a trefila e ao pátio de sucata 02 , os dados obtidos indicaram que as concentrações máximas mensais de PTS, relacionadas ao padrão de qualidade do ar primário diário $\left(240 \mu \mathrm{g} / \mathrm{m}^{3}\right)$, segundo Brasil (1990), não permaneceram dentro dos padrões somente em outubro de 2014, que apresentou um valor de $251,97 \mu \mathrm{g} / \mathrm{m}^{3}$ (Figura 4).

Figura 4 - Valores máximos e mínimos de concentração de PTS no AGV 4

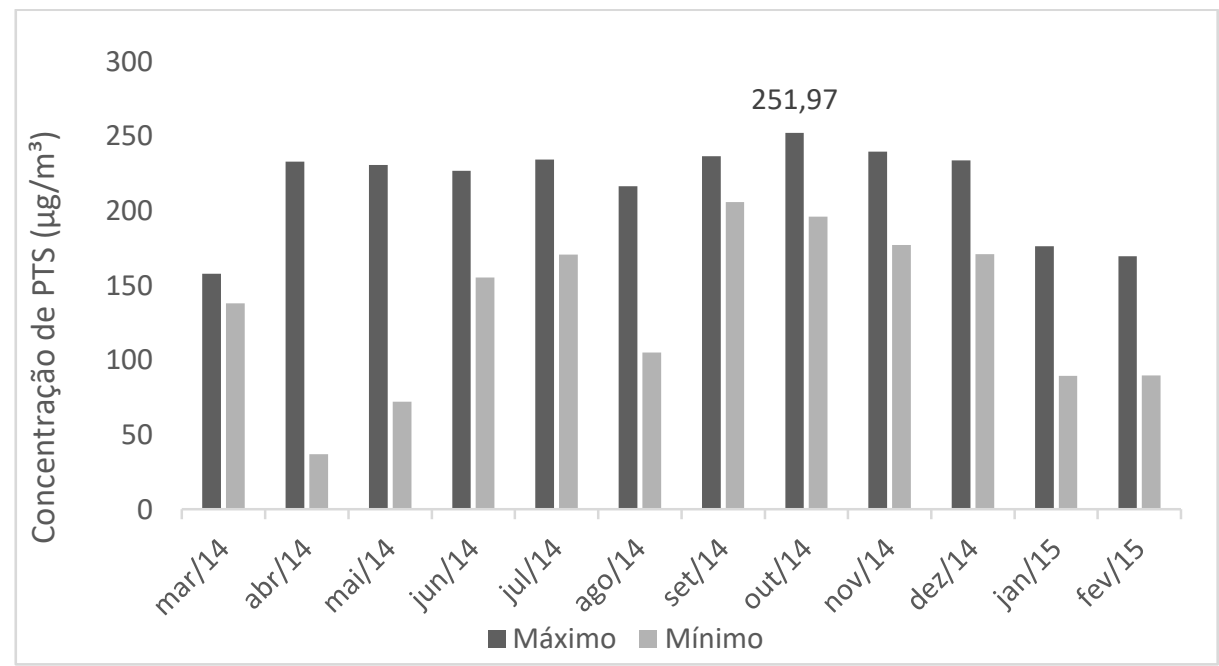

Fonte: Pesquisa de campo (2015) 
O valor médio encontrado para as concentrações das amostras de PTS analisadas no AGV 4 foi de $179,9 \mu \mathrm{g} / \mathrm{m}^{3}$, e os dados indicaram uma dispersão média, haja vista que o coeficiente de variação foi $28,48 \%$. Neste ponto, a variância foi igual a 2627,01 , e o desvio padrão $\pm 51,25$, os maiores valores encontrados, ou seja, os mais heterogêneos com relação à média, ainda que o maior valor do CV tenha sido do AGV 2.

Mas, neste caso, a distribuição foi assimétrica negativa, de $-0,61$, o que implica inferir que a concentração de PTS não excederá o padrão, fato não verificado, haja vista que o valor máximo excedeu em $11,97 \mu \mathrm{g} / \mathrm{m}^{3}$ o padrão, possivelmente por motivos semelhantes ao AGV 2, de acordo com Blume et al. (2014) e Zheng, Liu e Hsieh (2013).

\section{PRECIPITAÇÃO}

No período de setembro a dezembro, no qual foram observadas concentrações de PTS superiores ao limite permitido pela legislação em três dos quatro pontos, houve valores baixos para o índice pluviométrico (Figura 5).

Figura 5 - Relação de PTS com o Índice Pluviométrico

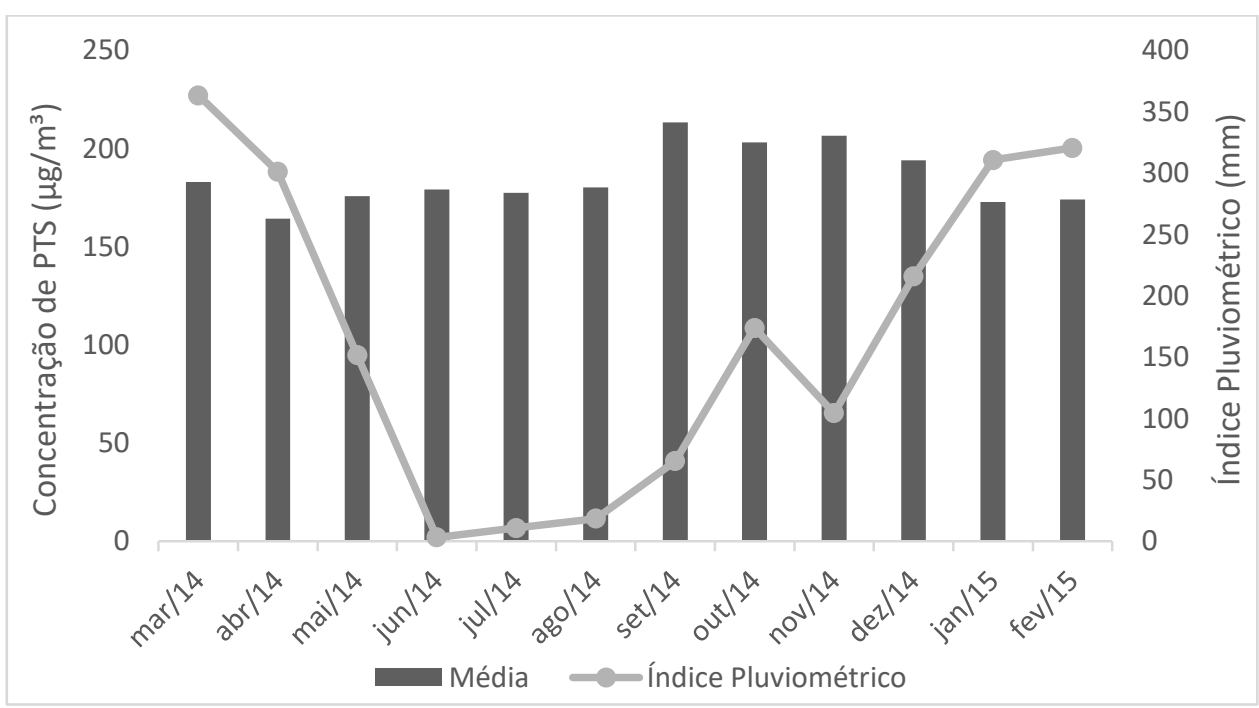

Fonte: INMET (2015)

Isso representou uma relação inversa, em que o $r=-0,96$, caracterizado por uma correlação muito forte. A mesma relação e caracterização foram observadas no período de maio a agosto, com $r=-0,79$, em que os valores para o índice pluviométrico foram os menores, porém neste período as concentrações não ultrapassaram o limite estabelecido, o que indica que este fator não é o único a relacionar-se com as concentrações de PTS.

Somado a isso, de janeiro a abril, período com os maiores valores para o índice pluviométrico, as concentrações determinadas de PTS não excederam o limite estabelecido por Brasil (1990), apesar do $r=0,93$, que retrata uma relação direta, diferente dos demais períodos, e correlação muito forte, o que corrobora com a indicação de mais fatores relacionados a concentração de PTS. 
Entretanto, considerando todos os meses de amostragem, o $r$ foi equivalente a $-0,32$, em que a relação é inversa e a correlação moderada. Portanto, os dados indicaram que, no período de amostragem analisado, quanto maior foi o índice pluviométrico menor foi a concentração de PTS, mas não fortemente.

Santos, Carvalho e Reboita (2016), em estudo efetuado na Região Metropolitana do Rio de Janeiro - RJ, concluíram que a ausência de precipitação, e ocorrência de ventos fracos e inversões térmicas na baixa troposfera atrelaramse a maioria das vezes em que o valor limite do Plano Nacional de qualidade do $\mathrm{Ar}$, para material particulado, foi excedido, fato que confirma os dados obtidos neste estudo.

\section{ALTO-FORNO}

Os valores e destaque na produção do alto-forno, foram os de julho, agosto, setembro, outubro, novembro e dezembro de 2014 , com produção em toneladas de $11.283,11.304,11.229,12.400,11.123$ e 11.634 , respectivamente. Nesse mesmo período, a quantidade média de partículas totais em suspensão foram $168,3 \mu \mathrm{g} / \mathrm{m}^{3} ; 177,5 \mu \mathrm{g} / \mathrm{m}^{3} ; 180,32 \mu \mathrm{g} / \mathrm{m}^{3} ; 213,3 \mu \mathrm{g} / \mathrm{m}^{3} ; 203,11 \mu \mathrm{g} / \mathrm{m}^{3} ; 206,49$ $\mu \mathrm{g} / \mathrm{m}^{3}$ e $194,02 \mu \mathrm{g} / \mathrm{m}^{3}$ (Figura 6).

Figura 6 - Relação das médias de PTS com a produção do alto-forno

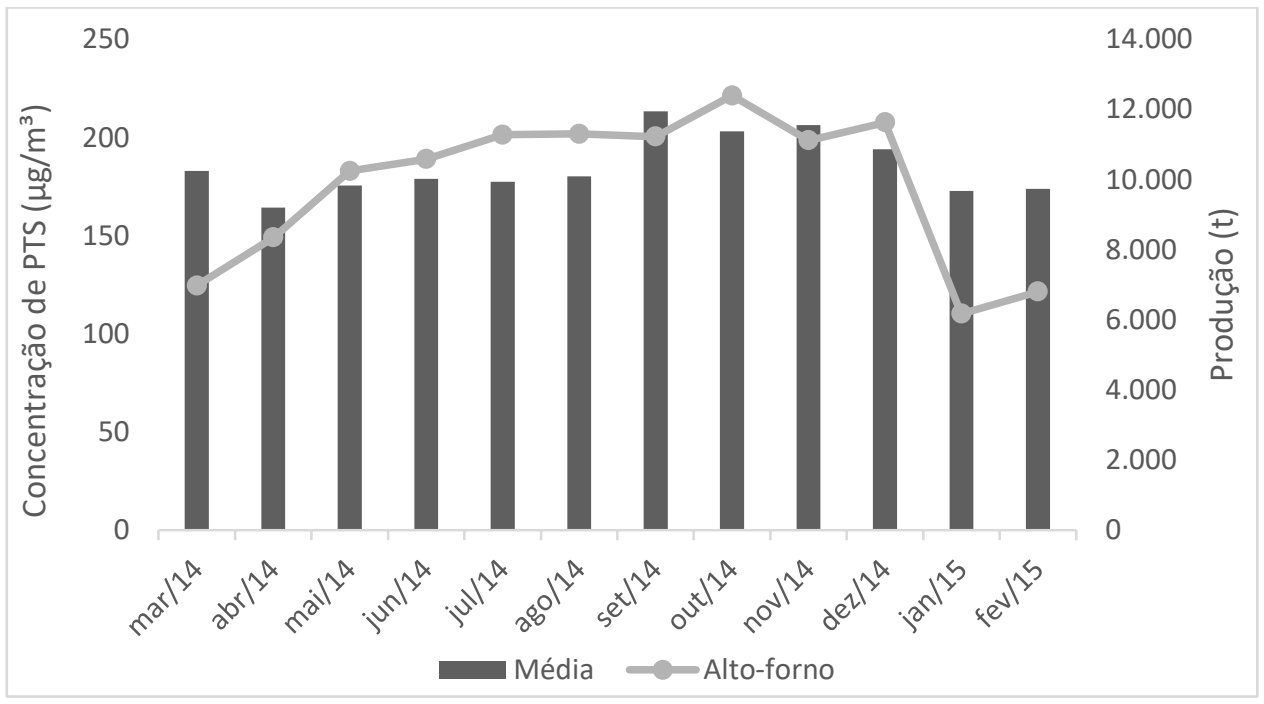

Fonte: Pesquisa de campo (2015)

No período analisado, os dados indicam que o intervalo entre setembro e dezembro, período de maiores médias, foi também o de maiores valores para o alto-forno. Isso aponta a existência da relação da influência entre a produção do alto-forno e a concentração de PTS. A associação destes dados refletiu em um $r=$ 0,6 , o que significa uma relação direta e correlação forte, conforme o exposto, com o maior valor apresentado entre os fatores de influência.

Rocha e Guimarães (2017), em pesquisa realizada em Volta Redonda - RJ, indicaram uma relação entre a produção advinda da atividade siderúrgica e a concentração de PTS, além da provável contribuição de particulados resultantes 
da rodovia próxima às estações de monitoramento, dados que ratificam os obtidos neste estudo.

\section{ACIARIA}

Os meses de maior produção da indústria na aciaria, ocorreram nos meses de maio, agosto, setembro, novembro e dezembro de 2014, com mensuração média geral de material particulado de $175,7 \mu \mathrm{g} / \mathrm{m}^{3}, 180,32 \mu \mathrm{g} / \mathrm{m}^{3}, 213,3 \mu \mathrm{g} / \mathrm{m}^{3}$, $206,49 \mu \mathrm{g} / \mathrm{m}^{3}$ e $194,02 \mu \mathrm{g} / \mathrm{m}^{3}$, respectivamente. Nestes meses as concentrações de PTS foram 175,69 $\mu \mathrm{g} / \mathrm{m}^{3}, 180,31 \mu \mathrm{g} / \mathrm{m}^{3}, 213,29 \mu \mathrm{g} / \mathrm{m}^{3}, 206,48 \mu \mathrm{g} / \mathrm{m}^{3}, 194,02$ $\mu \mathrm{g} / \mathrm{m}^{3}$ (Figura 7).

Figura 7 - Relação das médias de PTS com a produção da Aciaria

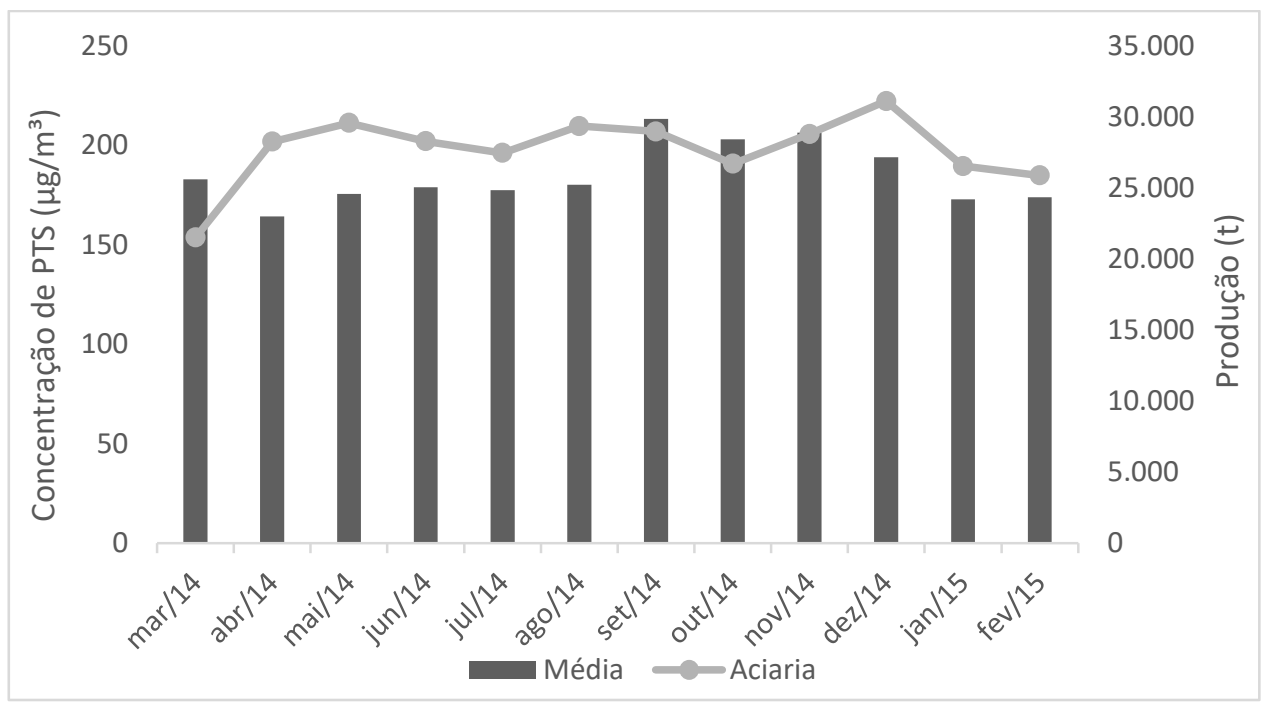

Fonte: Pesquisa de campo (2015)

A relação da produção aa aciaria com as concentrações de PTS foi direta, porém uma correlação fraca, de $r=0,19$. Dessa maneira, os dados indicaram que o aumento da mensuração de material particulado associa-se diretamente a ampliação da produção, só que de forma fraca, logo, este fator não foi representativo nas variações das concentrações de PTS. A pesquisa de Rocha e Guimarães (2017) também corrobora com os dados obtidos na relação destes fatores.

\section{CONCLUSÃO}

Diante disso, as concentrações máximas mensais de PTS no interior da usina siderúrgica excederam, três vezes, o padrão primário, ou seja, 1,27\% das 236 coletas amostradas. Igualmente, duas destas concentrações foram as maiores obtidas, no AGV 1 (alto-forno) e AGV 2 (laminação), respectivamente, os mais próximos à rodovia.

Portanto, a indústria conseguiu controlar e prevenir as emissões de partículas totais em suspensão na maior parte do período, mas não apresentou conformidade com o limite estabelecido pela Resolução CONAMA n. 3, de 28 de 
junho de 1990, pois excedeu mais de uma vez por ano o padrão primário estabelecido para PTS.

Ademais, verificou-se que o índice pluviométrico, a produção na aciaria e no alto-forno exerceram influência na concentração de PTS. Destes, o índice pluviométrico foi inversamente relacionado à concentração geral de PTS, e a produção tanto da aciaria quanto do alto-forno relacionou-se diretamente às PTS, sendo que, o fator de maior influência foi a produção no alto-forno. 


\title{
Determination of particulate material in the steel industry: case study
}

\begin{abstract}
Although the pig iron industry is of great importance for economic growth and employment generation, it is an aggravating factor in air quality, since it is related to the release of pollutants that affect the health of the population, such as particulates. These facts justify the research, which had the purpose of evaluating the amount of Total Suspended Particles (PTS) present in the atmospheric air in the surroundings of a steel park in Southeast of Pará, to compare with the values of CONAMA resolution no. 3 of 1990, and to relate these to the rainfall index and the production in the blast furnace and in the steel industry's steelworks. Thus, a Large Volume Sampler (AGV) was used for the quantification of the particulate material, and the procedures followed the guidance of NBR 9547 (ABNT) and the Energetics manual. The data obtained indicated that the industry controlled the material emanated during the majority of the analyzed period, however, it did not comply with the standard, since it exceeded the allowed amount of the established limit. In addition, the rainfall index, the production at the steelworks and the blast furnace had an influence on the PTS concentration.
\end{abstract}

KEYWORDS: Particulate Material. Steel industry. Large Volume Sampler. 
ALMEIDA, S. M. et al. Chemical characterization of atmospheric particles and source apportionment in the vicinity of a steelmaking industry. Science of the Total Environment, Madison, v. 521-522, p. 411-420, 2015. Disponível em: https://www.sciencedirect.com/science/article/pii/S0048969715003964. Acesso em: 30 jan. 2019. crossref

BLUME, K. K. et al. Genotoxicidade do ar em área urbana na região metropolitana de Porto Alegre, RS, Brasil. Revista Brasileira de Biociências, Porto Alegre, v. 12, n. 3, p. 158-163, jul./set. 2014.

BRASIL. Associação Brasileira de Normas Técnicas - ABNT. NBR 9547: Material particulado em suspensão no ar ambiente - Determinação da concentração total pelo método do amostrador de grande volume. 1997. Disponível em: http://www.esaat.com.br/docs/met_abnt/9547.pdf. Acesso em: 23 nov. 2018.

BRASIL. Resolução CONAMA n. 3, de 28 de junho de 1990. Publicada no DOU, de 22 de agosto de 1990, Seção 1, páginas 15937-15939. Complementa a Resolução no 5/89. Dispõe sobre os padrões de qualidade do ar, previstos no PRONAR. Disponível em: http://www2.mma.gov.br/port/conama/legiabre.cfm?codlegi=100. Acesso em: 23 nov. 2018.

CAMARA, V. F. Avaliação da efetividade dos limites de concentração de emissão de poluentes atmosféricos da indústria cerâmica na proteção da qualidade do ar. 2015. 163 f. Dissertação (Mestrado em Engenharia Ambiental) - Universidade Federal de Santa Catarina, Florianópolis, 2015.

CAMPOS, I. A. Z.; MARQUES, C. Direito ao meio ambiente e o necessário controle da poluição atmosférica: a inovação trazida pelo Estado do Espírito Santo. Revista Jurídica - UNICURITIBA, Curitiba, v. 2, n. 43, p. 534-559, 2016.

crossref

CARVALHO, L. S. P.; MESQUITA, D. P. P.; ARAÚJO, G. D. E. Sustentabilidade da siderurgia brasileira: eficiência energética, emissões e competitividade. BNDES Setorial, Rio de Janeiro, n. 41, p. 181-236, mar. 2015.

CAVALCANTI, P. P. S. Gestão ambiental na indústria siderúrgica - aspectos relacionados às emissões atmosféricas. 2012. 54 f. Trabalho de Conclusão de Curso (Bacharelado em Engenharia Metalúrgica) - Universidade Federal do Rio de Janeiro, Rio de Janeiro, 2012.

CETESB - Companhia Ambiental do Estado de São Paulo. Relatório de qualidade do Ar no Estado de São Paulo 2017. Série Relatórios. São Paulo: CETESB, 2018. 
CHERUBIN, M. R. et al. Dimensão da malha amostral para caracterização da variabilidade espacial de fósforo e potássio em Latossolo Vermelho. Pesquisa Agropecuária Brasileira, Brasília, v. 50, n. 2, p. 168-177, fev. 2015. crossref

COLVERO, D. A. et al. Avaliação da geração de resíduos sólidos urbanos no estado de Goiás, Brasil: análise estatística de dados. Engenharia Sanitária e Ambiental, Rio de Janeiro, v. 22, n. 5, p. 931-941, set./out. 2017. crossref

CONCEIÇÃO, A. F. G. Estudo da concentração dos poluentes atmosféricos de três lagoas e a correlação destes com variáveis meteorológicas. 2017. 94 f. Trabalho de Conclusão de Curso (Bacharelado em Engenharia Ambiental) - Universidade Tecnológica Federal do Paraná, Londrina, 2017.

CUNHA, A. T. D. Concepção de um lavador de gases aplicado no tratamento de efluentes gasosos de churrasqueira. 2016. 107 p. Trabalho de Conclusão de Curso (Bacharelado em Engenharia Sanitária e Ambiental) - Universidade Federal de Santa Catarina, Florianópolis, 2016.

DAPPER, S. N.; SPOHR, C.; ZANINI, R. R. Poluição do ar como fator de risco para a saúde: uma revisão sistemática no estado de São Paulo. Estudos Avançados, São Paulo, v. 30, n. 86, p. 83-97, jan./abr. 2016. crossref

DRUMM, F. C. et al. Poluição atmosférica proveniente da queima de combustíveis derivados do petróleo em veículos automotores. Revista Eletrônica em Gestão, Educação e Tecnologia Ambiental - REGET, Santa Maria, v. 18, n. 1, p. 66-78, abr. 2014. crossref

ENERGÉTICA - Indústria e Comércio LTDA. Amostrador de Grande Volume para Partículas Totais em Suspensão AGV PTS: manual de operação. Revisão 08. Rio de Janeiro: Energética, 2016. Disponível em: http://www.energetica.ind.br/wp/env1/wpcontent/uploads/2016/01/env1_manual-pts_rev_08.pdf. Acesso em: 08 jan. 2019.

FRANCOVÁ, A. et al. Evaluating the suitability of different environmental samples for tracing atmospheric pollution in industrial areas. Environmental Pollution, $v$. 220, parte A, p. 286-297, jan. 2017. Disponível em: https://www.sciencedirect.com/science/article/pii/S026974911631380X. Acesso em: 30 jan. 2019. crossref

GOMES, R. S. Análise dos impactos ambientais e da sustentabilidade em usinas siderúrgicas integradas a coque. 2016. 62 f. Trabalho de Conclusão de Curso (Bacharelado em Engenharia Metalúrgica) - Universidade Federal do Rio de Janeiro, Rio de Janeiro, 2016. 
INMET - Instituto Nacional de Meteorologia. Estações e dados: dados meteorológicos, estações automáticas. 2015. Disponível em: http://www.inmet.gov.br/portal/index.php?r=estacoes/estacoesAutomaticas. Acesso em: 23 nov. 2018.

JURAS, I. A. G. M. Os impactos da indústria no meio ambiente. In: GANEM, R. S. (Org.). Políticas setoriais e meio ambiente. Brasília: Câmara dos Deputados, Edições Câmara, 2015. 374 p.

KOYAMA, J. C. Monitoramento da qualidade do ar no município de Cascavel PR por meio de analisador portátil de gases. 2014. 75 f. Trabalho de Conclusão de Curso (Bacharelado em Engenharia Ambiental) - Universidade Tecnológica Federal do Paraná, Campo Mourão, 2014. crossref

MEDEIROS, A. B. S.; SARAIVA, A. L. B. C.; SABOIA, A. L. Qualidade do ar em Itajá/RN: quantificando os níveis de partículas totais em suspensão em ambientes externos. Revista Pensar Geografia, Mossoró, v. 2, n. 1, jul. 2018. crossref

MICROSOFT. Inc. Excel. Versão 1811. Software, 2016.

MONDO, L. S. Relação entre a qualidade do ar e possíveis efeitos à saúde. Estudo de caso: comunidade do Rio Carvão, Urussanga - SC. 2011. 109 f. Trabalho de Conclusão de Curso (Bacharelado em Engenharia Ambiental) Universidade do Extremo Sul Catarinense, Criciúma, 2011.

OLIVEIRA, A. A. B. Inventário das emissões atmosféricas na indústria siderúrgica. 2014. 85 f. Trabalho de Conclusão de Curso (Bacharelado em Engenharia Metalúrgica) - Universidade Federal do Rio de Janeiro, Rio de Janeiro, 2014.

PRODANOV, C. C.; FREITAS, E. C. Metodologia do trabalho científico: métodos e técnicas da pesquisa e do trabalho acadêmico. 2. ed. Novo Hamburgo: Feevale, 2013.

ROCHA, N. L. T.; GUIMARÃES, C. S. Estudo da qualidade do ar e a atividade siderúrgica na cidade de Volta Redonda. Cadernos UniFOA, Volta Redonda, n. 33, p. 25-36, abr. 2017.

SANTOS, T. C.; CARVALHO, V. S. B.; REBOITA, M. S. Avaliação da influência das condições meteorológicas em dias com altas concentrações de material particulado na Região Metropolitana do Rio de Janeiro. Engenharia Sanitária e Ambiental, Rio de Janeiro, v. 21, n. 2, p. 307-313, abr./jun. 2016. crossref 
SILVA, A. F.; VIEIRA, C. A. Levantamento das emissões de material particulado provenientes de fontes estacionarias de indústria siderúrgica, um estudo de caso. Revista Brasileira de Gestão e Engenharia, v. 2, n. 18, p. 23-35, jul./dez. 2018. Disponível em: http://periodicos.cesg.edu.br/index.php/gestaoeengenharia. Acesso em: 28 jan. 2019.

SILVA, N. G. et al. Reutilização e reciclagem de resíduos siderúrgicos: oportunidades de pesquisa de pesquisa e desafios do setor. In: FÓRUM INTERNACIONAL DE RESÍDUOS SÓLIDOS. 7., 2016, Porto Alegre. Anais... Porto Alegre: Instituto Venturi, jun. 2016.

SOARES, C. G. C. S. Caracterização físico-química de material particulado atmosférico coletado em Ipanguaçu, no Vale do Açu/RN. 2017. 91 f. Dissertação (Mestrado em Ciências Climáticas) - Universidade Federal do Rio Grande do Norte, Natal, 2017.

TRIOLA, M. F. Introdução à Estatística. Tradução: Vera Regina de Farias e Flores. 12. ed. Rio de Janeiro: LTC, 2017. Título original: Elementary statistics.

USEPA - UNITED STATES ENVIRONMENTAL PROTECTION AGENCY. Air Quality Criteria for Particulate Matter. [s.1.] v. I, 2004. Disponível em: http://cfpub.epa.gov/ncea/cfm/recordisplay.cfm?deid=87903. Acesso em: 01 fev. 2019.

ZHENG, Y.; LIU, F.; HSIEH, H. U-Air: when urban air quality inference meets big data. In: CONFERÊNCIA INTERNACIONAL DA ACM SIGKDD SOBRE DESCOBERTA DE CONHECIMENTO E MINERAÇÃO DE DADOS - KDD'13, 19., Illinois. Anais... Illinois, ago. 2013. p. 1436-1444. crossref

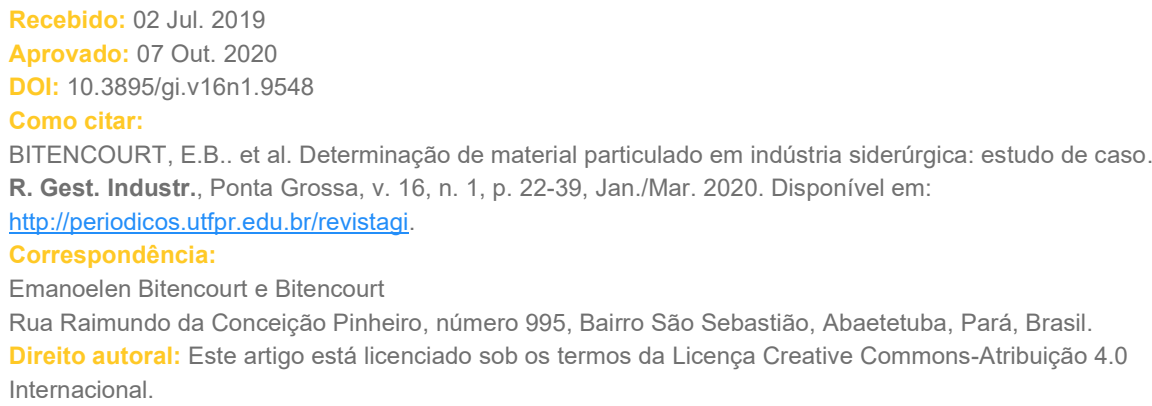

